Original Research Article

\title{
Adverse drug reaction to antiparkinson agents in Idiopathic Parkinson Disease: a prospective observational study in a Movement Disorder outpatient clinic
}

\author{
Firoz Thaha ${ }^{1}$, Reneega Gangadhar ${ }^{2}$, Thomas Iype ${ }^{3 *}$, Reeja Rajan ${ }^{4}$
}

\begin{abstract}
${ }^{1}$ Department of Pharmacology, Government Medical College, Thrissur, Kerala, India ${ }^{2}$ Department of Pharmacology, Sree Mookambika Institute of Medical Sciences,

Kulasekharam, Tamilnadu, India ${ }^{3}$ Department of Neurology, Government Medical College, Trivandrum, Kerala, India ${ }^{4}$ Clinical Psychologist, Government Medical College, Trivandrum, Kerala, India
\end{abstract}

Received: 23 January 2017 Accepted: 27 February 2017

\section{*Correspondence to:}

Dr. Thomas Iype,

Email: beenaiype@gmail.com

Copyright: (c) the author(s), publisher and licensee Medip Academy. This is an openaccess article distributed under the terms of the Creative Commons Attribution NonCommercial License, which permits unrestricted noncommercial use, distribution, and reproduction in any medium, provided the original work is properly cited.

\begin{abstract}
Background: Parkinson disease (PD) generally requires therapy for prolonged periods often with multiple drugs; drug-related adverse effects often add to the existing morbidity. Although, such ADRs are common, comprehensive information about their incidence, severity, and ultimate health effects are not available. The objective of the study was to analyze the pattern of occurrence of Adverse Drug Reactions (ADRs) in patients receiving anti-parkinson agents (APA) in a tertiary care hospital. We also aimed to assess the causality, severity and preventability of these ADRs.

Methods: This prospective, observational study with 6 month follow up was conducted among consecutive PD patients receiving anti parkinson agents attending the Movement disorder clinic of Neurology department between April $1^{\text {st }} 2011$ and September $30^{\text {th }}$ 2012. Tools used were ADR Reporting form of National Pharmacovigilance centre, WHO causality scale, Hartwig and Siegel scale to assess severity and Schumock and Thornton scale to assess preventability of ADRs. Descriptive statistics was used and the values were expressed in numbers and percentages.

Results: ADRs were experienced in 87 patients $(82.1 \%)$ out of 106 patients and most of these patients were on combination therapy (66\%). No gender difference in distribution of ADRs was observed. The most common reactions were sedation, dizziness, dry mouth and fatigue. The drug usage was in the order of pramipexole $(58.4 \%)$, levodopa+carbidopa $(55.7 \%)$, trihexyphenidyl $(28.3 \%)$, entacapone $(5.7 \%)$ and amantadine $(7.5 \%)$. Majority of the ADRs were mild level $1(71.1 \%)$. ADR was maximum with entacapone. Majority of ADRs belonged to the causality possible ADR category. All the ADRs came under the definitely or probably preventable category.

Conclusions: ADRs with antiparkinsonian drugs is common but mild and preventable.
\end{abstract}

Keywords: Adverse drug event, Causality, Observational study, Patient harm, Prospective studies

\section{INTRODUCTION}

Parkinson's disease (PD) is characterized by both motor and non-motor manifestations. ${ }^{1}$ Symptoms correlate with the site of affection of susceptible nerve cells and spread of pathological process in the brain. ${ }^{2,3}$
The choice of drug depends on whether it is tremor dominant or akineto-rigid parkinsonism, age of onset and presence of comorbidities. Levodopa is considered the standard therapy for PD due to its ability to control motor symptoms. Drug-related adverse effects are seen more frequently and earlier among young onset PD compared to older onset PD. ${ }^{4}$ There is a tradeoff between effect and adverse effects. Dopamine agonists is associated with less 
dyskinesia but at the cost of less symptomatic relief. ${ }^{5-7}$ Some medications are even associated with higher mortality. ${ }^{8}$ Various modified ways of giving levodopa have been tried to reduce the dyskinesia. ${ }^{9}$

ADR is a cause for prolonged hospitalization, human suffering, increased health expenditure and mortality. ${ }^{10,11}$ Hence, active surveillance system should be in place to monitor the pattern of ADR in hospitals. ${ }^{12}$ Comprehensive information about the pattern, severity, preventability of ADRs including dyskinesia and ultimate health effects with the currently used medications are not available in India. Therefore, this study was taken up to look at the pattern of ADRs and determine the frequency, severity and preventability of ADRs due to APDs.

\section{METHODS}

This is a prospective observational study conducted between April 2011 and September 2012 in the department of Neurology at Government Medical College Hospital, Thiruvananthapuram. The study protocol was approved by Institutional Human Ethics Committee. Confidentiality and anonymity of the patient's information was maintained during and after the study.

All the patients between 21-80 years of age of either gender, with a diagnosis of PD according to UK Parkinson's Disease Society Brain Bank clinical diagnostic criteria and who received anti parkinson drugs for any duration were included in the study. ${ }^{13}$ Patients who were taking drugs as a part of parkinsonism-plus syndromes and other movement disorders and who did not give consent were excluded from the study.

A written informed consent was obtained from the patient/ guardian/ relative. Patient's demographic details, their past history of adverse events, details of drug therapy and concomitant medication use were collected. These patients were evaluated for the presence of ADRs during a six month follow up visits to movement disorder clinic. When a suspected ADR was reported, data on that particular suspected reaction was collected and documented in Suspected ADR Reporting form of National Pharmacovigilance centre. Dechallenge and rechallenge were not done.

Causality (evaluation of causal relationship of drugs to its adverse effects) was assessed by WHO causality assessment scale based on some preformed description of the adverse reactions. ${ }^{14}$ ADRs were classified into certain, probable, possible, unlikely, unclassified and unclassifiable. Schumock and Thornton scale classified ADRs as definitely preventable, probably preventable and not preventable based on a set of questions for each level. ${ }^{15}$ Using modified Hartwig and Siegel scale, ADR was classified as mild, moderate or severe with various levels according to factors like requirement for change in treatment, duration of hospital stay and disability produced by adverse reactions. ${ }^{16}$ The data were compiled and tabulated using Statistical Package for the Social Science for windows (SPSS) version 19.0. Descriptive statistics was used for data analysis.

\section{RESULTS}

There were 106 patients with PD. Mean age of the patients was 57.26 years. Majority of patients (39 patients) were in the age group 50 -59 years (Table 1). Out of 106 patients, $87(82.1 \%)$ developed ADRs. Thirty five $(33 \%)$ patients had only single ADR. ADR was equally distributed in both sexes.

Table 1: Age wise distribution of study population.

\begin{tabular}{|lllll|}
\hline $\begin{array}{l}\text { Age } \\
\text { intervals }\end{array}$ & $\begin{array}{l}\text { No. of } \\
\text { patients }\end{array}$ & Percentage & $\begin{array}{l}\text { No of } \\
\text { ADRs }\end{array}$ & $\begin{array}{l}\text { ADRs per } \\
\text { cases }\end{array}$ \\
\hline $20-29$ & 1 & 0.94 & 1 & 1 \\
\hline $30-39$ & 3 & 2.83 & 5 & 1.7 \\
\hline $40-49$ & 16 & 15.09 & 28 & 1.8 \\
\hline $50-59$ & 39 & 36.79 & 95 & 2.4 \\
\hline $60-69$ & 35 & 33.02 & 49 & 1.4 \\
\hline $70-79$ & 11 & 10.38 & 22 & 2 \\
\hline $80-89$ & 1 & 0.94 & 1 & 1 \\
\hline Total & $\mathbf{1 0 6}$ & $\mathbf{1 0 0}$ & $\mathbf{2 0 1}$ & \\
\hline
\end{tabular}

The commonest APA used was pramipexole (Table 2). There were 201 ADRs observed. The top five ADRs were sedation (16.4\%), dizziness (14.4\%), dry mouth (12.9\%), fatigue $(8.4 \%)$ and dyskinesia $(7.0 \%)$. Majority of the ADRs $(71.1 \%)$ were "mild level 1", 20.9\% "moderate level 3" and 8\% "mild level 2" severity. "16 Moderate level 3 ADRs included dyskinesia, blurred vision, hallucination, dystonia, chorea, depression, facial tics and akathisia. Mild level 2 ADRs included freezing attacks and mental confusion. Mild level 1 ADRs were vomiting, insomnia, anxiety, constipation, sedation, fatigue, dizziness, anorexia, dry mouth, orange discoloration of urine, ankle edema and nausea.

Table 2: Incidence of ADRs on antiparkinsonian drugs.

\begin{tabular}{|llllll|}
\hline Drug & $\begin{array}{l}\text { Patients N } \\
(\%)\end{array}$ & $\begin{array}{l}\text { ADRs } \\
\text { incidence N }\end{array}$ & $\begin{array}{l}\text { ADRs per } \\
\text { drug }\end{array}$ & $\begin{array}{l}\text { Moderate } \\
\text { severity ADR }\end{array}$ & $\begin{array}{l}\text { Moderate severity ADR } \\
\text { per drug }\end{array}$ \\
\hline Amantadine & $8(07.5)$ & $14(13.2)$ & 1.8 & 1 & 0.13 \\
\hline Entacapone & $6(05.7)$ & $17(16)$ & 2.8 & 3 & 0.5 \\
\hline Levodopa /Carbidopa & $59(55.7)$ & $102(96.2)$ & 1.7 & 35 & 0.59 \\
\hline Pramipexole & $62(58.4)$ & $70(66)$ & 1.1 & 7 & 0.11 \\
\hline Trihexyphenidyl & $30(28.3)$ & $40(37.7)$ & 1.3 & 4 & 0.13 \\
\hline
\end{tabular}


Overall ADR was maximum with entacapone while it was least with pramipexole (Table 2). However, moderately severe ADRs were maximum with levodopa carbidopa and least with pramipexole.

ADRs belonged to either possible or unlikely. The majority of ADRs recorded belonged to the possible ADRs (Table 3). Cent percent of ADRs due to pramipexole belonged to possible category. On the contrary $41.2 \%$ of ADRs (entacapone) and $27.5 \%$ of ADRs (levodopa carbidopa combination) belonged to unlikely ADR category (Table 3).
Table 3: Causality assessment of ADRs.

\begin{tabular}{|llll|}
\hline Drug & $\begin{array}{l}\text { No. of } \\
\text { ADRs }\end{array}$ & $\begin{array}{l}\text { Possible } \\
\text { ADR(\%) }\end{array}$ & $\begin{array}{l}\text { Unlikely } \\
\text { ADR (\%) }\end{array}$ \\
\hline Amantadine & 14 & $13(92.9)$ & $1(7.1)$ \\
\hline Entacapone & 17 & $10(58.8)$ & $7(41.2)$ \\
\hline $\begin{array}{l}\text { Levodopa } \\
\text { carbidopa }\end{array}$ & 102 & $74(72.5)$ & $28(27.5)$ \\
\hline Pramipexole & 70 & $70(100.0)$ & $0(0.00)$ \\
\hline Trihexyphenidyl & 40 & $32(80)$ & $8(20)$ \\
\hline
\end{tabular}

The individual ADRs are given in Table 4.

Table 4: ADRs with individual drugs.

\begin{tabular}{|llllll|}
\hline ADR & $\begin{array}{l}\text { Amantadine } \\
\mathbf{N}(\%)\end{array}$ & $\begin{array}{l}\text { Entacapone } \\
\mathbf{N}(\%)\end{array}$ & $\begin{array}{l}\text { Levodopat } \\
\text { Carbidopa }\end{array}$ & $\begin{array}{l}\text { Pramipexole }(\%) \\
\mathbf{N}(\%)\end{array}$ & $\begin{array}{l}\text { Trihexyphenidyl } \\
\mathbf{N}(\%)\end{array}$ \\
\hline Akathisia & 0 & 0 & $4(6.8)$ & 0 & 0 \\
\hline Ankle odema & $3(37.5)$ & 0 & 0 & 0 & 0 \\
\hline Anorexia & 0 & $2(33.3)$ & $4(6.8)$ & 0 & 0 \\
\hline Anxiety & 0 & 0 & $5(8.5)$ & 0 & 0 \\
\hline Blurred vision & $1(12.5)$ & 0 & 0 & 0 & $4(13.3)$ \\
\hline Chorea & 0 & 0 & $1(1.7)$ & 0 & 0 \\
\hline Constipation & $3(37.5)$ & 0 & $7(11.8)$ & 0 & $2(6.7)$ \\
\hline Depression & 0 & 0 & $3(5.1)$ & 0 & 0 \\
\hline Dizziness & $2(25)$ & $2(33.3)$ & $17(28.8)$ & $18(29)$ & $5(16.7)$ \\
\hline Dry mouth & $4(50)$ & 0 & $9(15.2)$ & 0 & $17(56.7)$ \\
\hline Dyskinesia & 0 & $3(50)$ & $14(23.7)$ & $3(4.8)$ & 0 \\
\hline Dystonia & 0 & 0 & $8(13.5)$ & 0 & 0 \\
\hline Facial tics & 0 & 0 & $2(3.4)$ & 0 & 0 \\
\hline Fatigue & 0 & 0 & 0 & $17(27.4)$ & 0 \\
\hline Hallucination & 0 & 0 & $3(5.1)$ & $4(6.4)$ & 0 \\
\hline Insomnia & 0 & $3(50)$ & 0 & 0 & 0 \\
\hline Mental confusion & 0 & 0 & $2(3.4)$ & 0 & $4(13.3)$ \\
\hline Nausea & 0 & $1(16.7)$ & $6(10.2)$ & $5(8.1)$ & $3(10)$ \\
\hline Orange disc of urine & 0 & $3(50)$ & $3(5.1)$ & 0 & 0 \\
\hline Sedation & $1(12.5)$ & $2(33.3)$ & $12(20.3)$ & $23(37.1)$ & $5(16.7)$ \\
\hline Vomiting & 0 & $1(16.7)$ & $2(3.4)$ & 0 & 0 \\
\hline
\end{tabular}

$\mathrm{N}$ - number of patients, $\%=$ percentage

Vomiting, anxiety, constipation, insomnia and depression came under the category "definitely preventable" ADRs. Rest of the ADRs like sedation, fatigue, dyskinesia, dizziness, anorexia, dry mouth, blurred vision, orange discolouration of urine, hallucination, ankle edema, mental confusion, nausea, dystonia, chorea, facial tics and akathisia belonged to the category "probably preventable" ADRs. No ADRs were found in the "not preventable" category.

\section{DISCUSSION}

This study was undertaken to analyze the pattern of ADRs among the patients receiving antiparkinsonian drugs in the Neurology department of a tertiary care hospital.
Majority of our patients with PD (82.1\%) developed adverse reactions. This could be due to more advanced stage of PD in our cohort and the number/class of medication used. Majority had multiple ADRs with only a third of patients having single ADR. The mean age of our hospital cohort was similar to patients with adult onset PD. ${ }^{4,6}$ The ADRs were maximum in the 50 to 59 year age group. The high prevalence of ADRs could be explained by frequent use of pramipexole (62 patients, $58.4 \%$ ) which was associated with ADRs in $100 \%$ of our patient. The prevalence of neuropsychiatric ADRs has been reported to be more in patients on pramipexole compared to patients on levodopa or ropinirole. ${ }^{17}$ Population based studies have also shown that adverse reactions are more among 40 to 59 year group than among the elderly. ${ }^{18}$ Sedation was the commonest ADR. 
Excess day time sleepiness and sudden onset sleep are common ADRs. ${ }^{19}$ Dry mouth was a common side effect in the current study probably due to the use of trihexyphenidyl. Lower incidence rate of ADRs (19.7\%) compared to $82.1 \%$ in our study could be due to the mixed movement disorders (not exclusively PD) or due to the less severe cases of PD patients requiring less drugs in their study. ${ }^{20}$ Adverse reactions were more common in patients on levodopa. ${ }^{20} \mathrm{We}$ had maximum number of ADRs due to pramipexole which could be due to more frequent use of the drug.

Most frequently reported ADRs with levodopa+carbidopa in our study were dizziness $(28.8 \%)$, dyskinesia $(23.7 \%)$ and sedation $(20.3 \%$ ) (Table 4). Rascol in their study on PD patients with levodopa alone, observed sedation $(19.1 \%)$ and dyskinesia $(25.8 \%)$ in similar proportions to the present study but had lesser frequency of dizziness $(19.1 \%){ }^{6}$ However, nausea $(49.4 \%)$ and vomiting $(11.2 \%)$ were higher. This may be due to intake of levodopa+carbidopa combination in the present study which reduces the peripheral side effects of levodopa like nausea and vomiting. Causality of individual ADR assessed by WHO Causality Assessment Scale showed $72.5 \%$ of the reactions belong to the category "Possible" and $27.5 \%$ belong to the category "Unlikely". Unlikely ADRs might be due to adjuvant drugs taken with levodopa.

Sedation, dizziness and fatigue were frequently reported ADRs in patients taking pramipexole (Table 4). The frequency of sedation due to pramipexole (37.1\%) was consistent with findings by Parkinson study group. ${ }^{5}$ In the present study $29 \%$ of patients on pramipexole developed dizziness which was higher than earlier study. ${ }^{21}$ It might be due to concurrent intake of other drugs along with pramipexole in the present study. However, all ADRs to pramipexole belonged to the category "Possible".

Dry mouth $(56.7 \%)$ was the most frequent ADR observed in patients on trihexyphenidyl similar to that in literature. $^{22} 80 \%$ of the reactions belonged to the category "Possible". The rest $20 \%$ belonging to the category of "Unlikely" might be due to adjuvant drugs taken with trihexyphenidyl.

In the case of amantadine our study found a similar prevalence of dry mouth (50\%), constipation (37.5\%) and ankle edema $(37.5 \%)$ as in literature. ${ }^{22,23}$ Other ADRs reported include sedation, dizziness and blurred vision. Causality assessment showed most of the ADRs (92.9\%) belongs to the category "Possible" and only $7.1 \%$ belong to the category "Unlikely".

We found a higher prevalence of dyskinesia (50\%) and dizziness $(33.3 \%)$ in patients on entacapone. ${ }^{24}$ This difference might be due to small sample size and all of them were taking multiple drugs which could explain the high $(41.2 \%)$ prevalence of "Unlikely" causality category. Orange discoloration of urine $(50 \%)$, sedation
$(33.3 \%)$, anorexia $(33.3 \%)$, and vomiting (16.7\%) were also reported.

Assessment of preventability of ADRs in the current study showed that ADRs like vomiting, constipation, anxiety, insomnia and depression were definitely preventable and therefore with dosage titration these reactions can be effectively controlled. All other ADRs like dyskinesia and other psychotic reactions in parkinson disease were probably preventable due to poor predictability of ADRs and poorly understood mechanisms to explain their cause. ${ }^{25-27}$

Majority of the reported ADRs were of mild severity and hence, there would be no strong indication to change or withhold the drug. This was similar to mild to moderate severity ADRs reported with trihexyphenidyl. ${ }^{28}$

\section{Limitations}

One of the major limitations of the study was the restricted period of monitoring of ADRs, thus long term ADRs were not monitored. The lower frequency of ADRs could perhaps be explained by this fact. Most of the patients were on combination regimens and patients receiving monotherapy were less. So the causality assessment of ADRs reported low level of causal association.

\section{CONCLUSION}

The present study found that incidence of ADRs due to antiparkinsonian drugs was $82.1 \%$ and amongst them most of the patients were on combination therapy. Maximum incidence of ADRs was observed with pramipexole followed by levodopa+ carbidopa and trihexyphenidyl hydrochloride. Sedation was the most frequently reported adverse reaction followed by dizziness and dry mouth. Most of the adverse reactions of the treated drugs belonged to "Possible" or "Probable" category upon causality assessment. Majority of the adverse reactions were mild and probably preventable.

\section{Funding: No funding sources}

Conflict of interest: None declared

Ethical approval: The study was approved by the Institutional Ethics Committee

\section{REFERENCES}

1. Okubadejo NU, Ojo OO, Oshinaike OO. Clinical profile of parkinsonism and Parkinson's disease in Lagos, Southwestern Nigeria. BMC Neurology. 2010;10(1):1.

2. Braak H, Del Tredici K, Bratzke H, Hamm-Clement J, Sandmann-Keil D, Rüb U. Staging of the intracerebral inclusion body pathology associated with idiopathic Parkinson's disease (preclinical and clinical stages). Journal of Neurology. 2002;249(3):iii1-5. 
3. Braak H, Del Tredici K, Rüb U, de Vos RA, Jansen Steur EN, Braak E. Staging of brain pathology related to sporadic Parkinson's disease. Neurobiology of aging. 2003;24(2):197-211.

4. Kostic V, Przedborski S, Flaster E, Sternic N. Early development of levodopa-induced dyskinesias and response fluctuations in young-onset Parkinson's disease. Neurology. 1991;41(2 Part 1):202-5.

5. Parkinson Study Group. Pramipexole vs levodopa as initial treatment for Parkinson disease: a randomized controlled trial. JAMA. 2000;284(15):1931-8.

6. Olivier R, Brooks DJ, Korczyn AD, De Deyn PP, Clarke CE, Lang AE. A five-year study of the incidence of dyskinesia in patients with early parkinson's disease who were treated with ropinirole or levodopa. N Engl J Med. 2000;342:1484-91.

7. Holloway RG, Shoulson I, Fahn S, Kieburtz K, Lang A, Marek K, et al. Pramipexole vs levodopa as initial treatment for Parkinson disease: a 4-year randomized controlled trial. Arch Neurol. 2004;61(7):1044-53.

8. Lees AJ. Comparison of therapeutic effects and mortality data of levodopa and levodopa combined with selegiline in patients with early, mild Parkinson's disease. BMJ. 1995;311(7020):1602-7.

9. Stocchi F, Vacca L, Ruggieri S, Olanow CW. Intermittent vs continuous levodopa administration in patients with advanced Parkinson disease: a clinical and pharmacokinetic study. Archives of neurology. 2005;62(6):905-10.

10. Classen DC, Pestotnik SL, Evans RS, Lloyd JF, Burke JP. Adverse drug events in hospitalized patients: excess length of stay, extra costs, and attributable mortality. JAMA. 1997;277(4):301-6.

11. Nerurkar RP, Nadkar MY, Bichile SK. Need for monitoring adverse drug reactions. J Assoc Physicians India. 1998;46:673-4.

12. Bavdekar, Sandeep B. Monitoring adverse drug events: need for an active surveillance system. Indian pediatrics. 2004;41(8):860-0.

13. Hughes AJ, Daniel SE, Kilford L, Lees AJ. Accuracy of clinical diagnosis of idiopathic Parkinson's disease: a clinico-pathological study of 100 cases. Journal of Neurology, Neurosurgery and Psychiatry. 1992;55(3):181-4.

14. Zaki SA. ADR and causality assessment scales. Lung India: Official Organ of Indian Chest Society. 2011;28(2):152-3.

15. Schumock G, Thornton J. Focusing on the preventability of ADRs. Hospital Pharmacy. 1992;27(6):538.

16. Hartwig SC, Siegel J, Schneider PJ. Preventability and severity assessment in reporting ADRs. American Journal of Health-System Pharmacy. 1992;49(9):2229-32.

17. Perez-Lloret S, Bondon-Guitton E, Rascol O, Montastruc JL. Adverse drug reactions to dopamine agonists: A comparative study in the French Pharmacovigilance Database. Movement Disorders. 2010;25(12):1876-80.
18. Kumar N, Van Gerpen JA, Bower JH, Ahlskog JE. Levodopa-dyskinesia incidence by age of Parkinson's disease onset. Movement Disorders. 2005;20(3):3424.

19. Hobson DE, Lang AE, Martin WR, Razmy A, Rivest J, Fleming J. Excessive daytime sleepiness and sudden-onset sleep in Parkinson disease: a survey by the Canadian Movement Disorders Group. JAMA. 2002;287(4):455-63.

20. Mandal A, Chatterjee S, Das SK, Mishra A. Drug safety monitoring in patients of movement disorders of a tertiary care hospital. Indian $\mathrm{J}$ Pharmacol. 2010;42:249-51.

21. Pinter MM, Pogarell O, Oertel WH. Efficacy, safety, and tolerance of the non-ergoline dopamine agonist pramipexole in the treatment of advanced Parkinson's disease: a double blind, placebo controlled, randomised, multicentre study. J Neurol Neurosurg Psychiatry. 1999;66:436-41.

22. Parkes JD, Baxter RC, Marsden CD, Rees JE. Comparative trial of benzhexol, amantadine, and levodopa in the treatment of parkinson's disease. Journal of Neurology, Neurosurgery, and Psychiatry. 1974;37:422-6.

23. Dallos V, Stone P, Heathfield K, Allen F. The comparative value of amantadine and levodopa. Postgraduate Medical Journal. 1972;48:354-8.

24. Brooks DJ, Sagar H. Entacapone is beneficial in both fluctuating and non-fluctuating patients with Parkinson's disease: a randomised, placebo controlled, double blind, six month study. J Neurol Neurosurg Psychiatry. 2003;74:1071-9.

25. Price PA, Parkes JD, Marsden CD. Sodium valproate in the treatment of levodopa-induced dyskinesia. Journal of Neurology, Neurosurgery, and Psychiatry. 1978;41:702-6.

26. Thanvi B, Lo N, Robinson T. Levodopa-induced dyskinesia in parkinson's disease: clinical features, pathogenesis, prevention and treatment. Postgrad Med J. 2007;83:384-8.

27. Pintor L, Valldeoriola F, Bailles E, Marti MJ, Muniz A, Tolosa E. Ziprasidone versus clozapine in the treatment of psychotic symptoms in Parkinson disease: a randomized open clinical trial. Clin Neuropharmacol. 2012;35(2):61-6.

28. Horrocks PM, Vicary DJ, Rees JE, Parkes JD, Marsden CD. Anticholinergic withdrawal and benzhexol treatment in parkinson's disease. Journal of Neurology, Neurosurgery, and Psychiatry. 1973;36:936-41.

Cite this article as: Thaha F, Gangadhar R, Iype T, Rajan R. Adverse drug reaction to antiparkinson agents in Idiopathic Parkinson Disease: a prospective observational study in a Movement Disorder outpatient clinic. Int J Basic Clin Pharmacol 2017;6:901-5. 